\title{
THE GUIDING PRINCIPLES ON INTERNAL DISPLACEMENT AS INTERNATIONAL MINIMUM STANDARD AND PROTECTION TOOL
}

\author{
Walter Kälin*
}

In his report "In Larger Freedom", the UN Secretary-General, in March 2005 urged Member States to accept the Guiding Principles on Internal Displacement ${ }^{2}$ (hereinafter Guiding Principles) as "the basic international norm for protection" of internally displaced persons (hereinafter IDPs). Towards the end of July 2005, the Chairman of the UN General Assembly, after consultations with States, circulated a revised draft Declaration, based on this report, to be adopted by the Heads of State and Government gathered at the UN General Assembly 14 to 16 September 2005 to reaffirm the United Nations Millennium Declaration. Under the heading "Internally Displaced Persons", the draft proposes to recognize the Guiding Principles as "the minimum international standard for the protection

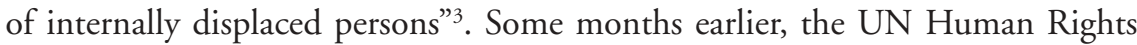
Commission used less strong language when it called the Guiding Principles "an important tool for dealing with situations of internal displacement", welcomed "the fact that an increasing number of States, United Nations agencies and regional and non-governmental organizations are applying them as a standard", and encouraged "all relevant actors to make use of the Guiding Principles when dealing with situations of internal displacement" ${ }^{\text {"4 }}$. Similar language can be found at the regional level. The Organization of African Unity (now the African Union) formally acknowledged the principles; the Economic Community of West African States (ECOWAS) called on its member states to disseminate and apply them; and in the Horn of Africa, the Intergovernmental Authority on Development (IGAD), in a ministerial declaration, called the principles a "useful tool" in the development of national policies on internal displacement. In Europe, the Organization for Security and Cooperation in Europe (OSCE) recognized that the principles as "a useful framework for the work of the OSCE" in dealing with internal displacement, and the Parliamentary Assembly of the Council of Europe urged its member states to incorporate the principles into their domestic laws5.

What then are the Guiding Principles? The "international norm" for the protection of internally displaced persons, the "minimum international standard" or just an "important tool" or "useful framework" for actors helping them to address situations of displacement adequately? This article argues that they are, at the same time, the minimum international standard (1.) and a practical tool (2.) for the protection of the rights of IDPs, and examines what steps could be taken to strengthen these functions further (3).

\footnotetext{
* Professor, University of Berne; Representative of the United Nations Secretary General on the Human Rights of Internally Displaced Persons; Member of the United Nations Human Rights Committee.
} 


\section{AN INTERNATIONAL LEGAL STANDARD FOR THE PROTECTION OF INTERNALLY DISPLACED PERSONS}

What are the rights of internally displaced persons (IDPs)? Unlike refugees, the internally displaced do not cross international borders. Although they have departed from their homes because of war, forced evictions or other reasons, they have not left the country whose citizens they normally are. They remain entitled to enjoy the full range of human rights as well as those guarantees of international humanitarian law that are applicable to the citizens of that country in general. However, IDPs have many special needs because of the fact of their displacement, and this requires special legal protection. At the same time, they are faced with the fact that no specific international convention exists for the protection of their rights and that none of the innumerable provisions of international human rights, humanitarian, and refugee law treaties explicitly addresses their plight. Thus, the challenge is to identify those guarantees and concepts implicit in the rich body of existing international law that respond to the special needs of IDPs, and to make this protection explicit.

This is exactly what the then Representative of the Secretary General on Internally Displaced Persons, Dr. Francis Deng, achieved when, in 1998, he presented the "Guiding Principles on Internal Displacement" to the UN Commission on Human Rights in response to a request to prepare an "appropriate framework" for addressing the plight of internally displaced persons ${ }^{6}$. This document details, in 30 principles, the specific meaning of the general human rights and humanitarian law guarantees for IDPs. It covers all three phases of internal displacement: the pre-displacement phase, the situation during displacement, and the phase of return or resettlement and reintegration. Thus, the Guiding Principles explicitly recognize a right not to be arbitrarily displaced, and spell out in detail the rights of those who are displaced. The Principles stress that a government cannot deny access by international humanitarian organizations to IDPs if it is unable or unwilling to provide the necessary assistance itself. Finally, the document underlines the right of IDPs to either return voluntarily to their homes (if this becomes possible) or to resettle in another part of the country.

As Representative Deng stressed at that time, the purpose of these Principles was "to address the specific needs of internally displaced persons worldwide by identifying rights and guarantees relevant to their protection" and thus to provide guidance to the Representative in carrying out his mandate; to States when faced with the phenomenon of displacement; to all other authorities, groups and persons in their relations with internally displaced persons; and to intergovernmental and non-governmental organizations when addressing internal displacement. Regarding their legal character he underlined that they "reflect and are consistent with international human rights law and international humanitarian law" and restate the relevant principles applicable to the internally displaced, which are now widely dispersed in existing instruments, clarify any gray areas and address gaps that may exist ${ }^{7}$. This statement was fully justified as the Guiding Principles were elaborated on the basis of a very detailed and thorough compilation and analysis 
of norms applicable to situations of internal displacement as contained in relevant human rights law, international humanitarian law and refugee law instruments ${ }^{8}$.

The Guiding Principles are not a binding document. Unlike declarations, resolutions or recommendations by international organizations, they have not been negotiated by States but prepared by a team of experts in close consultation with the concerned agencies and organizations and then submitted to the $\mathrm{Hu}$ man Rights Commission'. Thus, they do not even constitute typical soft law, i.e. they do not belong to those recommendations that rest on the consensus of States and thereby assume some authority that may be even taken into account in legal proceedings, but whose breach does not constitute a violation of international law in the strict sense, and thus does not entail State responsibility. Their soft law character stems not from the process of elaboration but from their content which is solidly grounded in existing international law. It is possible to cite a multitude of legal provisions for almost every principle ${ }^{10}$ which provided the drafters with strong normative guidance. Even where language was used that was not to be found in existing treaty law, no new law in the strict sense of the word was created in most cases. Instead, similar to a judge who has to decide to what extent a human rights guarantee invoked by an IDP does provide protection to that person, Dr. Deng's legal team tried to deduce specific norms from more general principles that are already part of existing international law.

An illustrative example of this technique is Principle 6 on "the right to be protected against being arbitrarily displaced". No existing instrument mentions such a right explicitly. However, humanitarian law prohibits displacement in some specific and limited situations, and human rights law, in a more general sense, guarantees not only freedom of movement but also the right to choose one's own residence, and thus, a right to remain ${ }^{11}$. A right not to be displaced can also be found in instruments on the rights of indigenous peoples ${ }^{12}$. From this it can be inferred that a right not to be arbitrarily displaced is already implicit in international law. Another example is the prohibition of return to situations of imminent danger ${ }^{13}$. Such a prohibition can be deduced from the prohibition of inhuman treatment, as it has been recognized by international monitoring bodies that it is inhuman to send a person to a country where he or she will face torture, death or another very serious human rights violation. However, as all the case law refers to return across international frontiers, a prohibition of return of internally displaced persons to dangerous areas within their own country needs to be articulated. Therefore, Principle 15 states the right of internally displaced persons "to be protected against forcible return to or resettlement in any place where their life, safety, liberty and/or health would be at risk". Such a principle, though not stated yet in an authoritative document, is in line with the spirit of existing international law and reflects its underlying principles.

The voluminous study on customary international humanitarian law recently published by ICRC ${ }^{14}$ confirms that the Guiding Principles, insofar as they are applied in situations of armed conflict, restate to a very large extent existing customary law. This study identifies 161 rules of customary law, most of which are applicable not only during international but also internal armed conflict, and 
which are also relevant to IDPs. Regarding Principle 6 (2) on arbitrary instances of displacement, Rule 129, e.g., confirms that deportations and displacement in times of armed conflict are strictly prohibited, "unless the security of the civilians involved or imperative military reasons so demand"; so is "ethnic cleansing" as a particularly serious form of unlawful displacement ${ }^{15}$. Rule 103 prohibits all forms of collective punishment which must also cover instances where displacement or the destruction or appropriation of property belonging to IDPs is used as punishment, and thus supports Principles 6(2)(e) and 21(2)(e). According to Rule 131, in "case of displacement, all possible measures must be taken in order that the civilians concerned are received under satisfactory conditions of shelter, hygiene, health, safety and nutrition and that members of the same family are not separated", thus confirming the customary character of many of the provisions underlying Guiding Principles 7(2), 17, 18 and 19. Principle 16 on missing persons and deceased family members has a firm foundation in Rules $112-115$ and 117. Rules 31 and 32 affirm the customary law character of the content of Principle 26 on respect for personnel engaged in humanitarian assistance, their transport and supply. Of particular importance is Rule 132 which, in accordance with Principle 28(1), reaffirms the right of displaced persons "to voluntarily return in safety to their homes and places of habitual residence as soon as the reasons for their displacement cease to exist." Finally, Rule 133 on the obligation to respect "the property rights of displaced persons" points to the customary law foundation of Principles 21 and 29(2) in situations of armed conflict ${ }^{16}$.

These and other examples show that the Guiding Principles on Internal Displacement are drafted in a way that carefully restate existing international law with a view to making more general norms applicable to the specific situation of internal displacement. Because of that solid foundation, as well as the breadth of rights covered and the wide acceptance the Guiding Principles have found ${ }^{17}$, it can persuasively be argued that they are the minimum international standard for the protection of internally displaced persons.

\section{A PRACTICAL TOOL FOR THE PROTECTION OF INTERNALLY DISPLACED PERSONS}

How can this minimum international standard for the protection of internally displaced persons be used in practice? What has become known as the "protection gap" is one of the main problems faced by millions of internally displaced persons throughout the world. A recent study found that the United Nations' approach to IDPs is "still largely ad hoc and driven more by the personalities and convictions of individuals on the ground than by an institutional system-wide agenda", in addition to suffering "from a lack of political and financial support from UN headquarters and UN member states"18. At UN headquarters level, the study identified "a reluctance by senior UN officials, both in the field and at headquarters, to advocate for the rights of the displaced in an effective and assertive manner", "a sharp division within the UN between the humanitarian and political sides of the house, with protection relegated in nearly every case to the humanitarian agen- 
cies, which often found themselves working at cross-purposes with other UN officials who wielded significantly more political and economic power" and "serious under funding of protection programming" ${ }^{19}$. In addition, many countries faced with internal displacement are unwilling to protect the rights of those affected or, while possessing the requisite political will, lack the necessary capacities and tools including laws, policies and institutions to do so.

How can the Guiding Principles on Internal Displacement contribute to effectively dealing with this protection gap? They go beyond a simple compilation and restatement of those human rights and humanitarian law guarantees that are applicable to situations of internal displacement. Rather, they provide a fullfledged framework for identifying protection needs and for planning, implementing and monitoring protection activities.

Often, one of the reasons why international agencies as well as national governments fail in providing protection to internally displaced persons is a limited understanding of what protection means. Governments at times deny protection because of narrow definitions of who is an IDP, e.g. by limiting this categorization to victims of insurgents to the detriment of those fleeing the armed forces of the State, or to displaced persons belonging just to one of several ethnic communities. International agencies and organizations, on the other hand, sometimes insist that protection is limited to issues of saving lives in emergency situations or equate the character and degree of protection with the extent and limitations of their own mandates.

The Guiding Principles help to overcome these limitations. For one, they stress that the notion of "internally displaced person" includes all those who have left their homes and places of habitual residence involuntarily, whatever the circumstances, and have not crossed an international frontier ${ }^{20}$. Secondly, they address the full range of rights that may become relevant for protection against displacement, during displacement and in the context of return or resettlement, once durable solutions become possible. In doing so, they reflect the fact that internally displaced persons remain citizens of the country they are in and do not lose, as a consequence of their being displaced, the rights provided to the population at large.

The broad conceptual approach of the Guiding Principles thus facilitates a broad understanding of protection. While the material assistance afforded by humanitarian organizations and agencies contributes to ensuring the basic necessities of life, humanitarian assistance and human rights protection are not identical. Rather, protection of the rights of internally displaced persons encompasses, according to the IASC IDP Policy, "all activities aimed at ensuring full respect for the rights of the individual in accordance with the letter and the spirit of the relevant bodies of law, i.e. human rights law, international humanitarian law and refugee law" ${ }^{21}$. In this regard, governments have the obligation to ensure that (i) violations are prevented, (ii) that they cease, (iii) that they do not reoccur, and that (iv) victims of violations are provided with effective remedies including reparation, rehabilitation or compensation ${ }^{22}$. UN agencies, international non-governmental organizations and other international actors may, besides doing advocacy 
on behalf of the rights of the displaced, work through the government in order to assist it in its efforts to protect the rights of IDPs, complement the government's efforts, or, if need be, substitute for the government in the absence of its willingness or ability to protect the rights of the displaced. As highlighted by the IASC IDP Policy, these protection activities of the international actors can be responsive, i.e. "about stopping, preventing or mitigating a pattern of [ongoing] abuse", remedial, i.e. "aimed at restoring people's dignity and ensuring adequate living conditions subsequent to a pattern of violation, through rehabilitation, restitution, compensation and repair ", or environment building, i.e. "aimed at creating and/or consolidating an environment - political, social, cultural, institutional, economic and legal - conducive to full respect for the rights of the individual"23.

From a rights perspective, it is important to stress that protection of internally displaced persons must not be limited to securing the survival of IDPs but relates to all relevant guarantees provided to them by international human rights and humanitarian law and reflected in the Guiding Principles. For practical reasons, these rights can be divided into four categories, namely:

(1) rights related to physical security and integrity (e.g., protection of the right to life and to be free of torture and cruel and inhuman treatment, assault, rape, arbitrary detention, disappearances, kidnapping, and threats concerning the above ${ }^{24}$;

(2) rights related to the basic necessities of life (e.g., the rights to food, potable water, shelter, adequate clothing, adequate health services, and sanitation $)^{25}$;

(3) rights related to other civil and political protection needs (e.g., the rights to religious freedom and freedom of speech, personal documentation, political participation, access to courts, and freedom from discrimination $)^{26}$;

(4) rights related to other economic, social and cultural protection needs (e.g., the rights to work, receive restitution or compensation for lost property, and to be provided with or have access to education $)^{27}$, and

The first and second categories respond to the needs for physical survival and bodily integrity. The third and fourth respond to the need to recognize the inherent dignity of human beings. The Principles relating to the different categories highlight that these needs are often different from those who remain in their homes and places of residence. Thus, regarding the first and second categories, the practice of "ethnic cleansing" (Principle 6), attacks on camps (Principle 10) or the needs of IDPs to get basic shelter and housing (Principle 18) are intrinsically linked to the forced movement of people. Regarding the rights of the third category, the displaced are facing specific problems that are different from those of the non-displaced population, e.g. in the areas of discrimination because of their being displaced (Principle 1), of access to lost documentation (Principle 20) or the exercise of their voting rights (Principle 22). Fourth category rights are especially important in the context of restitution of or compensation for lost property (Principle 29). 
All these rights are equally important, as mere survival without dignity is intolerable, whereas dignity cannot be enjoyed without survival. Accordingly, this categorization is not an attempt to create a hierarchy of needs and corresponding rights. Rather, it makes clear that internally displaced persons need protection not only in the emergency phase of a displacement crisis but also beyond it.

However, it is clear that, in practice, not all rights are equally important in each situation of displacement. Which of the several protection needs of IDPs are in the forefront, depends very much on the specific context. It also is clear that agencies and organizations have specific and limited mandates and therefore cannot address all protection needs at the same time. Similarly, the ministry or department responsible for internally displaced persons in a specific country may not have the authority or capacity to deal with all problems faced by IDPs. However, the Guiding Principles make it possible to systematically analyze and identify the main protection needs by asking to what extent the displaced face problems regarding each of the Principles. They then facilitate the tasks of determining the necessary actions and assigning respective roles and responsibilities to each of the respective actors, i.e. the government, UN agencies, international nongovernmental organizations etc. In this way, comprehensive policies and plans of action can be developed that cover all the relevant protection needs of internally displaced persons in a given situation and do not neglect the protection of rights that are not in the forefront of humanitarian action.

\section{TOWARDS INCORPORATION INTO DOMESTIC AND REGIONAL} LAW

The Guiding Principles, while neither being a declaration nor constituting a binding instrument, draw, as shown above, their authority from the binding provisions of international human rights and humanitarian law upon which they are based and which they reflect by restating in greater detail many of the existing legal provisions which respond to the specific needs of internally displaced persons. Experience shows that their connection to existing law is recognized and acknowledged by many governments which, at the same time, feel more comfortable to discuss their application without having to enter into the issue of legal obligations. For this and other reason ${ }^{28}$, it is doubtful, at least for the time being, whether turning the Guiding Principles into a binding UN Convention would be feasible or even desirable. However, this does not mean that no steps to enhance the standing of the Guiding Principles should be taken. Attempts to incorporate them into domestic laws and policies and into regional international law are especially promising in this regard.

It is particularly encouraging that several States including Angola, Burundi, Colombia, Peru, the Philippines, Sri Lanka and Uganda have made explicit reference to the Principles in their national laws and policies on internal displacement. However, as encouraging as this development is, some of the resulting laws and policy documents have not made very clear how the rather abstract general principles of international law articulated by the Guiding Principles should translate 
into concrete action on the ground. The Representative on the Human Rights of Internally Displaced Persons therefore plans to assist governments by developing, in broad consultation with relevant actors, a manual that would provide law and policy makers with detailed guidance as to the content, institutional arrangements and procedures necessary to make the Principles operational at the domestic level. This is in line with the UN Secretary-General's proposal in his reform report that the UN Member States "commit themselves to promote the adoption of [the Guiding P] rinciples through national legislation" ${ }^{29}$.

Another important development can be observed in Africa. In 2004, the Executive Council of the African Union adopted a decision requesting the Commission of the Union to "collaborate with relevant cooperating partners and other relevant stakeholders to ensure that Internally Displaced Persons are provided with an appropriate legal framework to ensure their adequate protection and assistance" ${ }^{30}$. It is not decided yet what form such framework should take. Reference to a "legal" text, however, indicates that the idea is to elaborate a binding instrument. Taking into account that while IDPs often experience situations that are similar to those of refugees, their legal situation is fundamentally different from those who no longer enjoy the protection of their own country but rely on the mercy of the country of refuge and, therefore, are in need of the substitute international protection provided on the basis of refugee law conventions. It would therefore not be appropriate to opt for an additional protocol to the African Refugee Convention of 1969. A freestanding Convention incorporating all of the Guiding Principles probably is politically too ambitious and legally not necessary to the extent that many of the rights covered by the Principles are already enshrined in the 1981 African Charter on Human and Peoples' Rights. Thus, it might be worthwhile to explore the possibility of an optional protocol to the Charter that would focus on incorporating those principles into the regional human rights law that are not or not clearly enough covered by the Charter. Such principles include, inter alia, Principle 1(1), stating that internally displaced persons "shall not be discriminated against in the enjoyment of any rights or freedoms on the ground that they are internally displaced", Principle 6 on the prohibition of arbitrary displacement, Principle 7 on the modalities of (lawful) displacement, Principle 9 on the protection of indigenous peoples, minorities peasants, pastoralists and other groups with a special dependency on or attachment to their lands, Principle 12(2) on confinement in camps, Principle 13 on the recruitment of children, Principle 16 on missing persons, Principle 15 on the right to seek safety in another part of the country or abroad and to be protected against forcible return to situations of danger, Principle 20(2) on documents, and Principles 28 on voluntary return in safety and with dignity. As outlined above, some of the provisions contained in these principles are already part of customary international humanitarian law. To include them into a regional human rights instrument would have the double advantage of expanding their applicability to peace-time and to allow for their monitoring by the African Commission on $\mathrm{Hu}$ man and Peoples' Rights and the African Court. 
In the mid term, an optional protocol to the regional human rights convention might also be a way for Europe where, within the framework of the Council of Europe, a Working Party on IDPs set up by CAHAR (Committee of experts on legal aspects of territorial asylum, refugees and stateless persons) is presently exploring ways to strengthen the implementation of the Guiding Principles. It does not have a mandate to elaborate a legal instrument but it would certainly be welcome news if the working party, as part of its conclusions, would propose to create new hard law in areas not yet covered by the European Human Rights Convention and the European Social Charter.

Whatever the outcome of these discussions and efforts, it is encouraging to see that Africa and Europe are taking the lead in recognizing the need to strengthen the legal basis for the implementation of the guarantees contained in the Guiding Principles. It is to be hoped that other regional organizations and ultimately the UN will follow suit and take similar these initiatives in the long term.

\section{Notes}

A/59/205, 21 March 2005, para. 210.

Guiding Principles on Internal Displacement, Addendum to the Report of the Representative of the Secretary-General, Mr. Francis M. Deng, submitted pursuant to Commission resolution 1997/39, 11 February 1998, UN Doc E/CN.4/1998/53/Add.2.

3 At the time of this writing it was not know whether the General Assembly would adopt this text.

4 E/CN.4/2005/L.60, 14 April 2005, para. 7.

5 See Roberta Cohen, "The Guiding Principles on Internal Displacement: An Innovation in International Standard Setting", Global Governance 10 (2004), 459-480, at 469-70.

6 Commission on Human Rights Resolution 1996/52 (UN Doc E/CN.4/RES/1996/52, 19 April 1996) called "upon the Representative of the Secretary-General to continue, on the basis of his compilation and analysis of legal norms, to develop an appropriate framework in this regard for the protection of internally displaced persons".

7 Report of the Representative of the Secretary-General, Mr. Francis M. Deng, submitted pursuant to Commission resolution 1997/39, Addendum, Guiding Principles on Internal Displacement, E/CN.4/1998/53/Add.2 11 February 1998, Introductory note to the Guiding Principles, paras. 9 and 10.

8 Compilation and Analysis of Legal Norms, Report of the Representative of the Secretary-General on Internally Displaced Persons, UN Doc. E/CN.4/1996/52/Add. 2 (1995) and Part II, Legal Aspects Relating to Protection Against Arbitrary Displacement, UN Doc. E/CN4/1998/53/Add.1 (1998).

$9 \quad$ For the drafting history of the Guiding Principles see, e.g., Cohen, op.cit., at $460-465$.

10 See Walter Kälin, Guiding Principles on Internal Displacement, Annotations, Washington D.C. 2000, highlighting in detail the legal basis for each of the Principles.

11 See article 12(1) of the International Covenant on Civil and Political Rights, articles 49 and 147 Geneva Convention IV, Articles 51(7), 78(1) and 85(4) of Protocol I, Articles 4(3)(e) and 17 of Protocol II.

12 Article 16 of the ILO Convention No. 169 concerning Indigenous and Tribal Peoples in Independent Countries.

13 See Article 3 of the 1984 Convention against Torture and the case law regarding Article 7 of the $1966 \mathrm{Cov-}$ enant on Civil and Political Rights and Article 3 of the 1950 European Convention on Human Rights.

14 Jean-Marie Henckaerts/Louise Doswald-Beck, Customary International Humanitarian Law, Volume I: Rules, ICRC/Cambridge University Press 2005.

15 Id., at 457. On "ethnic cleansing" see 461-2.

16 Other rules relevant for the protection of property of IDPs are Rule 50 (prohibition "of destruction and seizure of property of an adversary [...], unless required by imperative military necessity"), Rule 52 (prohibition of pillage) and Rule 103 (prohibition of collective punishment).

17 See the references above in the introduction to this article.

18 Protect or Neglect: Toward a More Effective United Nations Approach to the Protection of Internally Displaced Persons, An Evaluation by Simon Bagshaw and Diane Paul, Brookings-SAIS Project on Internal Displacement and the Inter-Agency Internal Displacement Division of OCHA, November 2004, at 3. The study is available online at www.brookings.edu/fp/projects/idp/protection_survey.htm.

19 Id., at 4 . 
20 According to the Guiding Principles internally displaced persons are "persons or groups of persons who have been forced or obliged to flee or to leave their homes or places of habitual residence, in particular as a result of or in order to avoid the effects of armed conflict, situations of generalized violence, violations of human rights or natural or human-made disasters, and who have not crossed an internationally recognized State border".

21 Implementing the Collaborative Response to Situations of Internal Displacement, Guidance for UN Humanitarian and/or Resident Coordinators and Country Teams, Inter-Agency Standing Committee, December 2005, at 41.

22 Report of the Representative of the Secretary-General on the human rights of internally displaced persons, Walter Kälin, submitted pursuant to Commission on Human Rights resolution 2004/55, E/CN4/2005/84, 31 December 2004, para. 43. For the categorization of these obligations under international human rights law see Human Rights Committee, General Comment No. 31 [80], Nature of the General Legal Obligation Imposed on States Parties to the Covenant, CCPR/21/Rev.1/Add.13, paras. 6, 7,15.

23 Implementing the Collaborative Response, op.cit., at 44.

24 This category is addressed by Principles 6 (2)(a), 8, 10, 11, 12, 13, 15(a) und (d), 28(1), etc.

25 See mainly Principles 7(2) 18 and 19.

26 E.g. Principles 14, 15b und (d), 16, 17, 20, 22(a), (c), (d) und (e).

27 E.g. Principles 21, 22(b), 23, 29.

28 For the reasons why the former Representative refrained from proposing elaboration of a convention on the human rights of IDPs, see Walter Kälin, "How hard is soft law? The Guiding Principles on Internal Displacement and the Need for a Normative Framework", in: Recent Commentaries about the Nature and Application of the Guiding Principles in Internal Displacement, The Brookings-CUNY Project on Internal Displacement, April 2002, at 4-7.

29 "In Larger Freedom: Towards Development, Security and Human Rights for All", A/59/205, 21 March 2005, para. 210.

30 African Union, Executive Council, Fifth Ordinary Session 25 June - 3 July 2004, Addis Ababa, Ethiopia, Decision $127(\mathrm{~V})$ on the Situation of Refugees, Returnees and Internally Displaced Persons, reproduced in Doc. EX.CL/Dec. 93 - $164(\mathrm{~V})$. 